\title{
Assessing Freshwater Use Impacts in LCA, Part II: Case study of broccoli production in the UK and Spain
}

\author{
Llorenç Milà i Canals • Ashok Chapagain · Stuart Orr · Jonathan Chenoweth · Assumpció \\ Anton · Roland Clift
}

\section{Preamble}

In this series of two papers, methodological approaches to the assessment of freshwater resources use in life cycle assessment (LCA) are discussed. In Part I, Milà i Canals et al. (2009) discussed operational methods and characterisation factors, and suggested an approach to give a more representative indication of the impacts of water use. This paper (Part II) illustrates this approach for a case study of broccoli produced in the United Kingdom (UK) and Spain.

\begin{abstract}
Background, aim, and scope Milà i Canals et al. (2009, referred to as 'Part I' in this paper) showed that impacts associated with use of freshwater must be treated more rigorously than is usual in life cycle assessment (LCA), going beyond the conventional consideration only of "blue" water (i.e. irrigation and other abstractions), and suggested an operational method to include the impacts on freshwater ecosystems (FEI, Freshwater Ecosystem Impact) and abiotic resource depletion (FD, Freshwater Depletion). The inclusion of water-related impacts in LCA is of paramount importance, particularly for agricultural systems due to their large water consumption worldwide. A case study of UK consumption of broccoli grown in the UK and Spain is presented here, to illustrate the method suggested in Part I.

Materials and methods Water Footprint (WF) and life cycle impact assessment (LCIA) methods presented in Part I are applied to six different and synchronic supply chains providing broccoli during the British colder months (NovemberApril); four of these chains refer to broccoli produced in Spain and the other two are based on frozen British produce. In addition, four UK-based supply chains delivering fresh broccoli from April to November are studied to provide a yearround perspective.

Results Using WF accounting methods helps to provide a richer picture of the total water consumption associated with growing broccoli. Including the volumes of water consumed in the life cycle inventory (LCI), assessed following the WF approach (evaporative uses of irrigation water and soil moisture), shows that the total water consumption does not vary greatly between UK and Spanish broccoli production. However, when impact assessment indicators based on the Water Use Per Resource (WUPR) ratio are applied, water use in Spain is shown to be much more critical, with significantly higher impact for Spanish cultivation. While the largest component of water use in Spain is linked to irrigation, the study reveals other important uses in the life cycle of vegetables, namely direct use of water for cooking and sanitation, land use effects on the water cycle, and electricity production.

Discussion The results highlight the importance of distinguishing between different water volumes and sources in the different LCA phases: LCI (with and without full WF consideration) and LCIA. Traditional LCI results may be misleading when comparing irrigated systems in regions with differing water scarcity. The WF estimates are more relevant for sourcing strategies, as they show the total water requirements of crops including both irrigation water use as well as the use of green water (effective rainfall stored as soil moisture). Finally, LCIA results show the potential impacts of water consumption on freshwater ecosystems and future freshwater availability.

Conclusions This methodological framework improves the representation of impacts associated with water use in life cycle assessment (LCA). This helps in identifying the hotspots of the production system in terms of potential impacts to freshwater ecosystems, as well as in identifying where investments for water-saving may have the greatest benefit. In addition, this approach addresses a regional specific issue, water scarcity, which may often be closer to critical thresholds than other environmental impacts.

Recommendations and perspectives The method should be tested with further case studies in order to confirm the suitability and necessity of the LCI modelling requirements and LCIA characterisation factors such as the explicit inclusion of evaporative water losses. The WF approach can benefit from experience of systems analysis gained in LCA, whilst LCA may benefit from the detailed accounting framework embodied in the WF approach, as illustrated in this paper. Because the purposes of the two tools are different, they will continue to evolve separately, but complementarity in application should guide this development.
\end{abstract}


Keywords broccoli $\bullet$ food supply chain $\bullet$ water footprint $\bullet$ water resource $\bullet$ freshwater ecosystem impact $\bullet$ freshwater depletion • Life Cycle Assessment $\bullet$ Life Cycle Inventory $\bullet$ Life Cycle Impact Assessment

L. Milà i Canals $(\triangle)$

Unilever - Safety \& Environmental Assurance Centre, Colworth Park, Sharnbrook, Bedfordshire, MK44 1LQ, UK

email: Llorenc.Mila-i-Canals@unilever.com

L. Milà i Canals $\cdot$ J. Chenoweth $\cdot$ R. Clift

Centre for Environmental Strategy, University of Surrey, GU2 7XH Guildford (Surrey), United Kingdom

A. Chapagain

WWF - UK, Panda House, Weyside Park, GU7 1XR Godalming (Surrey) United Kingdom

S. Orr

WWF- International, Avenue du Mont-Blanc, 1196 Gland, Switzerland

A. Anton

IRTA, ctra. Cabrils, km 2, 08348 Cabrils (Barcelona), Spain

\section{Background, aim, and scope}

It is now widely recognised that agricultural production represents a significant component of anthropogenic environmental impacts and resource use, so that life cycle assessment (LCA) of agricultural systems is of paramount importance. Milà i Canals et al. (2007a) and Edwards-Jones et al. (2008) discuss the limitations of focusing concern on single issues such as food miles, energy use or greenhouse gas emissions. The importance of dissipative water use in agricultural production is increasingly recognised, given that increasing population and changing dietary habits, exacerbated by demand for bioenergy, are increasing pressure on land and water use. From a strategic sourcing perspective, it is important to better understand water requirements of crops to determine areas best suited for production, particularly given predicted changes in rainfall and water availability as a result of global climate change. Geo-spatially and temporally differentiated 'total water use per tonne of crop' is also relevant in virtual water (VW) trade discussions, concerned with the water embodied in international trade.

Milà i Canals et al. (2009, referred to as 'Part I' in this paper) showed that impacts associated with use of freshwater, including irrigation and other abstractions, must be treated more rigorously in LCA, going beyond the conventional consideration only of abstracted water (i.e. surface or ground water). In the Water Footprint (WF) approach, 'blue water' is defined as an evaporated volume of water supplied from surface or groundwater sources, whereas 'green water' is the volume of evaporated soil moisture maintained by rainfall. Withdrawal of blue water for agriculture is $2,664 \mathrm{billion}^{3} / \mathrm{yr}$. This is about $70 \%$ of the total blue water withdrawal globally (FAO 2003). However, total water evaporation from agriculture is 6,390 billion $\mathrm{m}^{3} / \mathrm{yr}$, of which $83 \%$ is green water (Chapagain and Hoekstra, 2004). In addition, water use may lead to impacts whose spatial dependency must be considered in comparing localised and globalised food supply chains.

Milà i Canals et al. (2009) proposed a new methodology based on distinguishing between these two categories of water use, including land use effects through impacts on freshwater ecosystems (Freshwater Ecosystem Impact, FEI) and abiotic resource depletion (Freshwater Depletion, FD). FEI is defined as the volume of 'ecosystem-equivalent' water, referring to the volume of water likely to affect ecosystems, while FD represents the resource scarcity value of abstraction from groundwater bodies (relative to the conventional reference element antimony). A coherent set of equations was proposed to quantify the WF of a product in terms of the evaporated volumes of green and blue water (and non-evaporated blue water use) in the agricultural stages of the life cycle. In addition, Part I proposed methods to quantify the volume of rainwater rendered unavailable for ecosystems due to land use interventions and to distinguish evaporative and non-evaporative uses of water in other processes in the product life cycle (e.g. electricity production). The volumes linked to environmental impacts (evaporative blue water use; land use effects on water availability for ecosystems; non-evaporative blue water use for FD) are then characterised with spatially dependent factors (see section 3.2) to derive FEI and FD. For Freshwater Ecosystem Impact (FEI), two different indicators were suggested: Water Use Per Resource (WUPR, or criticality ratio as defined by Alcamo et al. 2000) and the Water Stress Indicator (WSI). The WUPR relates to the amount of water used in a country or regions to the total available resources, whereas the WSI follows the same logic but considers only the water resources available once ecosystem water requirements have been subtracted. The WSI is thus more meaningful for ecosystem impacts than WUPR; however it has not been possible to find the necessary data to define WSI for the river basins relevant to this case study so that only WUPR has been used here. In the case of FD, Part I suggests how Abiotic Depletion Potentials (ADP) can be calculated for the use of freshwater from over-abstracted aquifers.

The present paper illustrates how the approach proposed by Milà i Canals et al. (2009) can provide a more informative comparison of localised and globalised food supply chains by examining the effects of freshwater use on ecosystems and resources using the approach and characterisation factors developed in Part I for a case study of UK consumption of 
broccoli from production sites in the UK and Spain. These case study areas and the broccoli crop have been described in Muñoz et al. (2008) and Milà i Canals et al. (2008) using common LCA impact categories, including a simple life cycle inventory (LCI) indicator for water use. Section 2 gives a brief description of the materials and regions studied, while section 3 sets out the calculation approach and the parameters used to implement the method suggested in Part I. Section 4 presents the LCI results with the water volumes calculated with the new approach. This leads to life cycle impact assessment (LCIA) results obtained applying the characterisation factors developed in Part I and section 3.2. Section 5 discusses the importance of distinguishing between different types of water uses and finally section 6 offers conclusions and suggests needs for further research.

\section{Materials}

Production of broccoli (the Italica cultivar group of the species Brassica oleracea) was assessed in a previous study for two countries, the UK and Spain, including distribution to UK retailers and consumption in UK homes; complete results are given by Milà i Canals et al. (2008). We focus here on water use in these supply chains.

The specific cases assessed were two different UK broccoli growers in Lincolnshire (UK5 and UK6) and two large broccoli producers in Spain's principal horticultural region, Murcia (ES1 and ES2), producing mainly for the UK. Broccoli does not need to be irrigated in the UK but must be irrigated in Murcia for optimum yield due to the low rainfall in this region during the selected growing season. In Murcia, ES1 uses gravity irrigation and has higher water inputs (20\% higher in the first crop and twice as much in the second) than ES2, which uses drip irrigation. Each of the four producers studied obtains two crops of broccoli from the same field in each year, identified by numbers after the farm code (e.g. UK5-1; UK5-2).

Broccoli is produced in open fields in the UK from March/April to October/November, whereas Spanish broccoli is grown between October/November and April/May and arrives in the UK from November to April. Therefore, Spanish broccoli can only be fairly compared to British broccoli supplied in the same season, which is achieved by freezing (i.e. the ES supply chains are only comparable to the UK-Fr supply chains). Thus, in order to evaluate comparable supply chains for broccoli, the frozen broccoli supply chain was evaluated for the UK, and a suffix 'Fr' is added to these supply chain codes (UK5-2-Fr; UK6-2-Fr).

\section{Methods}

Part I gives a full explanation of methods to quantify water use in production systems and the characterisation factors that may be used to identify associated impacts. The following sections discuss specific details of the current study.

\subsection{Life Cycle Inventory}

Foreground system: In the broccoli supply chains studied, most water is used in the cropping stage. A coherent methodological framework is needed to estimate the water use of a crop grown under different conditions such as open field, covered (e.g. glass house, plastic cover), rain-fed, irrigated, etc. In this work, the different components of water used in agriculture have been calculated following the approach described in Part I (section 4.1), which enhances previous studies by using local climate data for each production region to account for variations within and between countries. Details and formulae used are explained in Chapagain et al. (2006) and Chapagain and Orr (2008; 2009). The first step is to calculate total crop water requirement (evaporative demand) of the crop at any specific production site using the method suggested by FAO (Allen et al. 1998). The evaporative demand of the crop is provided by soil moisture. If there is enough rainfall to maintain the soil moisture to meet the crop water requirement, the irrigation water requirement is zero; the total water use is then $100 \%$ green. However, in the absence of sufficient rainfall, supplementary irrigation is needed. The dissipative irrigation requirement is estimated as the difference between the evaporative demand and the part of the local precipitation which is stored in the soil rather than running off the field. Non-dissipative use of irrigation water is estimated as the proportion lost through leakage or running off the field. The total quantities of irrigation water applied and evaporated are obtained as integrals over the entire crop growth period. In this work, direct water use was calculated using the method presented in Chapagain and Orr (2009), summarised in Part I, which uses the CROPWAT model (FAO 1993) with climate data from CLIMWAT ${ }^{1}$ (FAO 1993) and IWMI (2007). Local crop characteristics were used together with data on rainfall availability and irrigation water use during crop production. The modelling parameters for different production

\footnotetext{
${ }^{1}$ As CLIMWAT does not cover the UK, the necessary input files to the CROPWAT model were prepared using IWMI's online climate service model (IWMI 2007).
} 
sites in this study are presented in Table 1 and the results are summarised in Table 2. To illustrate the method, the calculation steps for the Spanish site ES1-1 are presented here.

\section{Table 1}

For production in Spain, the necessary climate data to run the CROPWAT model are collected from CLIMWAT. From

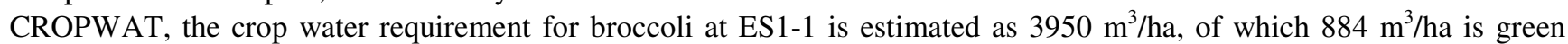
water and the balance, $3066 \mathrm{~m}^{3} / \mathrm{ha}$, is blue water. As the irrigation water supply is only $3000 \mathrm{~m}^{3} / \mathrm{ha}$ and irrigation efficiency, defined here as the volume of water effectively evaporated by plants divided by total irrigation water supplied, is estimated as only $70 \%$ (gravity irrigation) ${ }^{2}$, the net volume of blue water available to the crop is only $2100 \mathrm{~m}^{3} / \mathrm{ha}^{2}$ Evaporative blue water is estimated as the smaller of the requirement and the supply, in this case the supply of $2100 \mathrm{~m}^{3} / \mathrm{ha}$. The total water evaporated in crop production is thus 2100 (blue) plus 884 (green), i.e. $2984 \mathrm{~m}^{3} /$ ha. The return flow, which is the volume of water not available for crop evaporation as a result of leakages from the irrigation system and runoff, is estimated as $3000-2100$, i.e. $900 \mathrm{~m}^{3} /$ ha. The virtual water content of broccoli production $\left(\mathrm{m}^{3} / \mathrm{t}\right)$ in Spain is calculated by dividing the respective crop water uses, expressed in $\mathrm{m}^{3} /$ ha, by crop yield, expressed in $\mathrm{t} / \mathrm{ha}$.

\section{Table 2}

On average, broccoli from the UK evaporates $136 \mathrm{~m}^{3}$ of water per tonne of production which is $100 \%$ green water, whereas broccoli from Spain evaporates $162 \mathrm{~m}^{3}$, of which $110 \mathrm{~m}^{3}$ is blue water and $52 \mathrm{~m}^{3}$ is green water. These differences in evaporation are obviously due to different climate conditions. Note that these are not to be interpreted as representative averages; to properly describe 'UK' or 'Spanish broccoli', estimates weighted by production in different farms and regions would be needed. Spanish production is not only water intensive but also less water efficient, as the average leakage flow is around $30 \mathrm{~m}^{3} /$ tonne of broccoli. However, the main difference between the water footprint of broccoli from the UK and Spain lies in the kind of water used: UK production uses green water (evaporation supported from rainfall) whereas Spanish production predominantly uses blue water (irrigation water from surface and ground water).

Broccoli cultivation represents the main land use in all product systems. Specific parameters have been used to derive land use effects on the water-cycle for the UK and Spanish crop fields, based on the average rainfall in each region (646 litres $\mathrm{m}^{-}$ ${ }^{2}$ year $^{-1}$ in Lincolnshire and 296 litres $\mathrm{m}^{-2}$ year $^{-1}$ in Murcia) together with the differences in the usable proportion of precipitation for arable and forested land (Milà i Canals et al. 2009, Table 1): In Lincolnshire ('high rainfall') 73\% of rainfall is 'lost' from arable land and only 67\% from forested land (which is the reference land use); thus the land use effects on rainwater availability in Lincolnshire are $(73-67) \% * 646=39$ litres $\mathrm{m}^{-2} \mathrm{year}^{-1}$; i.e. for every $\mathrm{m}^{2}$ occupied over one year for agriculture, 39 less litres are available than in the reference situation. In Spain ('low rainfall') 93\% of precipitation is lost from arable land and $83 \%$ from forested land; i.e. (93-83)\% $\% 296=30{\text { litres } \mathrm{m}^{-2} \text { year }}^{-1}$ are lost due to land use for agriculture.

In addition to water evaporated by crops, groundwater (and sometimes surface water, depending on availability) evaporates from reservoirs where water is stored before use. As explained in Milà i Canals et al. (2009) this is considered as a 'water land use' with the evaporation attributed to the system studied. In the case of ES2, all the irrigation water used in the farm $900,000 \mathrm{~m}^{3} /$ year - comes from the aquifer; the reference system is groundwater from which evaporation is zero. The reservoir evaporation is calculated based on its surface area of ca. 10,000 $\mathrm{m}^{2}$ with a mean annual evaporation potential of 1,400 litres $\mathrm{m}^{-2}$ year $^{-13}$ Thus, the evaporation loss is $1,400 * 10,000 / 900,000$, equal to 15.5 litres per $\mathrm{m}^{3}$ of irrigation water actually delivered, representing a loss of $1.6 \%$; i.e. before the $2,500 \mathrm{~m}^{3} /$ ha are delivered to ES2-1 (of which $2,250 \mathrm{~m}^{3} / \mathrm{ha}$ are effectively evaporated and $250 \mathrm{~m}^{3} /$ ha are returned through leakage, Table 2), a further $15.5 * 2,500=38,750$ litres $\left(39 \mathrm{~m}^{3}\right)$ have been evaporated from the reservoir.

Background system: In order to obtain a life-cycle perspective of the impacts from freshwater use, the database used for the background system (ecoinvent 1.03) had to be adapted to differentiate between evaporative and non-evaporative uses of water. Applying a simple cut-off rule, this detailed assessment was applied only to those processes using more than $1.5 \mathrm{~L}$ of water per $\mathrm{kg}$ of broccoli on the plate, equivalent to $2 \%$ of the freshwater use in the systems using least water, i.e. UK5 and UK6 sold fresh. For these processes, the proportion of evaporated water was estimated for the particular operations involved (Table 3).

\section{Table 3}

The water associated with electricity production (accounting for about $50 \%$ of blue water in the UK systems and $12-13 \%$ in the ES systems) is mainly linked to thermal power plants, where water is evaporated mainly for cooling. Following Milà $i$ Canals et al. (2009), the evaporation is estimated as $1 \mathrm{~kg}$ of water per $2.4 \mathrm{MJ}$ energy dissipated as heat. Considering the efficiencies in the distribution networks and the total freshwater use reported in ecoinvent for the different voltages used in the studied systems, the following values of evaporative and non-evaporative water use per kWh have been used:

GB, electricity, medium voltage at grid: $2.8 \mathrm{~kg}$ evaporative use $+18.8 \mathrm{~kg}$ non evaporative use

GB, electricity, low voltage at grid: $3.1 \mathrm{~kg}$ evaporative use $+20.7 \mathrm{~kg}$ non evaporative use

\footnotetext{
${ }^{2}$ The efficiency figure would be lower yet if losses in the distribution grid (canals; pipes; etc.) were included.

${ }^{3}$ Meteorological data were provided by Sección de Climatología y Relaciones con los Usuarios Centro Meteorológico Territorial en Murcia (data for the period 1997-2006).
} 
ES, electricity, medium voltage at grid: $2.8 \mathrm{~kg}$ evaporative use $+33.8 \mathrm{~kg}$ non evaporative use

In addition to irrigation water and cooling water in electricity generation, tap water (e.g. for cooking; toilet flushing) represents one of the biggest inputs to the systems studied. The process 'RER: tap water, at user' reports a total input of $1.13 \mathrm{~kg}$ water for each $\mathrm{kg}$ water delivered, corresponding to a dissipative loss of $11.5 \%$ of the blue water used (Althaus $e t$ al. 2004). This loss may be due to leakage from pipes and/or evaporation. We have treated all the water lost as evaporated, and added an extra $1 \%$ to represent evaporative losses for the various uses of tap water; thus $12.5 \%$ of the input tap water has been treated as evaporative use and the rest as non-evaporative. It should be noted that these are very low total loss estimations: in both Spain and the UK urban water networks average losses of about 22\%, although the main part of those losses are non-evaporative. However, treating all distribution losses as evaporative is an overestimate, as they mostly occur underground; this is proposed as the best estimate available in the absence of more complete information. In addition, some tap water uses may be mostly evaporative (e.g. some farmers use tap water for irrigation) but this should be addressed on a case by case basis.

Finally, water use reported for cardboard packaging (corrugated board) refers to process water, for which a generic evaporative loss of $5 \%$ has been used. Green water use for forestry has not been included; it can be significant (Van der Walt et al. 2004) but was considered to be beyond the scope of this study.

\subsection{Life Cycle Impact Assessment}

As explained above, FEI has been calculated using the WUPR indicator. The WUPR is $32 \%$ for Spain and $6.5 \%$ for the UK (Part I); i.e. 32\% of blue water resources are used in Spain compared to $6.5 \%$ in the UK so that each $\mathrm{m}^{3}$ of blue water used in Spain is assessed as having an impact five times as high as in the UK. Many background processes only have the geographical reference of "Europe". For Europe, the WUPR is estimated as $15 \%$ from total water use $\left(324 \mathrm{~km}^{3} / \mathrm{year}\right.$ in 2000 according to FAO 2003) and the total internal resources (2112 $\mathrm{km}^{3} /$ year). The UK, Spanish and European WUPR values suffice for the illustrative purposes of this paper, although.WUPR values may vary significantly within a country. For example, Muñoz et al. (submitted) show values for different Spanish catchments ranging from e.g. 40\% (Ebro River) to $167 \%$ (Segura River). Thus, if farms from different regions were being compared, it would be desirable to use regional rather than national WUPR values.

For FD, Custodio (2002) points out that the aquifers in Murcia are reportedly overexploited (depletion rate of $12510^{6} \mathrm{~m}^{3} \mathrm{yr}^{-}$ ${ }^{1}$ from remaining reserves of $10,00010^{6} \mathrm{~m}^{3}$, data for 1995). Therefore, the formula for the Abiotic Depletion Potential suggested in Part I (based on the net depletion rate) is used to derive the ADP for all groundwater uses in the Murcian crops as $1.7710^{8} \mathrm{~kg} \mathrm{Sb}-\mathrm{eq} / \mathrm{kg}$ groundwater.

\section{Results}

\subsection{Life Cycle Inventory Results}

Figure 1 shows the results obtained by complementing the LCA results with the WF approach set out in Part I, introducing the distinction between evaporative blue water use and land use effects and incorporating evaporative green water use and non-evaporative blue water use. The principal novelties introduced by this approach lie in showing explicitly the evaporative dissipation of green water and the land use effect on freshwater availability, which accounts for infiltration and evapo-transpiration in the production system relative to a reference land use (Part I). According to the approach used in this study, non-evaporative blue water use, which ranges from $14 \%$ to $36 \%$ of total water use in these systems, is only significant from the perspective of abiotic resource depletion where water is abstracted from overexploited aquifers, as in broccoli cultivation in Murcia.

Fig. 1

ES1 has higher non-evaporative water use than ES2, due to the more inefficient irrigation system: ES1 uses gravity irrigation, with only $70 \%$ of water available for take-up by the crop. For UK production, sufficient rainfall is available during the critical growth period to meet most of the demand, minimizing the need for irrigation. Water use is lower for UK5 production than for UK6 because the crop yield is relatively low in UK6 $(9,600 \mathrm{~kg}$ per hectare compared with 15,600 $\mathrm{kg}$ per hectare for UK5; Table 1) while the evaporation per ha is similar in the two systems (see Table 2). Less significantly, planting at UK5-1 starts in mid-March whereas UK6-1 starts in early April; this makes the effective rainfall available at UK5-1 less than at UK6-2 (144 mm and $158 \mathrm{~mm}$ per crop season respectively) because there is less rainfall in the period March-May than in April-June. 


\subsection{Life Cycle Impact Assessment Results}

Once the freshwater volumes which have significance for impacts on ecosystems (i.e. evaporative blue water use and land use effects) have been quantified in the LCI (Fig. 1), the spatial-dependent characterisation factors (section 3.2) are applied to these volumes. Figure 2 shows the results for 'Freshwater Ecosystem Impact' (FEI). Applying the characterisation factors derived in Part I and section 3.2 emphasises the differences between Spanish and UK systems due to two effects. First, green water use (main water use in the UK, see Fig. 1) has a zero characterisation factor (see Part I). The dominant use of blue water is in cropping in Spain (see Fig. 1) while the characterisation factor WUPR for blue water is 0.32 for Spain and 0.065 for the UK (see section 3.2).. The effect from land uses throughout the life cycle is significant, but only dominates the results for British fresh broccoli where it causes 50-60\% of the FEI. Due to the differences in WUPR, the land use effects are also more pronounced in Spain.

Fig. 2

For overall depletion of Abiotic Resources (ADP), once the water use from Murcia's over-abstracted aquifer is considered, it completely dominates the results (Table 4). In fact, it causes the contributions to ADP by the Spanish farms to be twelve orders of magnitude above the contributions from the UK farms, which are dominated by energy resources (oil, gas, etc.). This result suggests that the importance of water scarcity may be locally higher than the scarcity of globally traded resources such as oil and gas. The differences observed between Spanish farms are due to different water uses and origins: ES1 use a mixture of surface and groundwater, while ES2 reported use of groundwater only.

\section{Table 4}

Figure 3 shows how the results for FEI compare with the other impacts assessed in the study: in this specific case study, FEI and ADP reveal the clearest differences between the Spanish supply chains and the frozen British supply chains.

Fig. 3

\section{Discussion}

This paper illustrates an approach to assessing impacts resulting from freshwater use which affects all phases of LCA. First, basing the LCI on the approach accepted in the water footprint (WF) community as suggested in Part I and applied here, enables the total water demand from plants to be included, covering both blue and green water. Applying this combined LCI/WF approach over the full product life cycle has the advantage of distinguishing between types and sources of water (rain, surface, ground etc); this is particularly significant for the agricultural stages of the life cycle, because it enables local data on climate and water evaporation by crops to be incorporated. Distinguishing impacts on ecosystems (FEI) and on future availability of freshwater resources (FD) is another important contribution of this approach. The environmental significance of consuming rainwater (green water) is minor, as discussed in Part I; indeed, a similar amount of soil moisture (stored rain water) will be used by different crops and/or natural ecosystems regardless of the cropping system. Therefore, evaporated rainwater is not further considered in the LCIA phase (section 4.2); this constitutes a key difference between the WF and the LCA method suggested here. A possible drawback of this method is the difficulty in incorporating inherent variability in agricultural production, although this is true of any approach to assessing the environmental impacts of agriculture, including LCA.

For irrigated fresh vegetables, blue (irrigation) water used in the cropping stage dominates the results. For more processed foods (e.g. frozen vegetables), other uses of blue water become relevant, such as electricity generation. Second, in the impact assessment phase, only blue water use has been considered here, characterised with country-specific factors, while green water use is given a zero impact for the reasons set out above and in part I. However, it may be argued that the use of green water in certain areas may relate to impacts on freshwater ecosystems. For now we suggest that this is perhaps best captured through land use effects, which show the net effect of the production system on green water availability; however, more case studies are needed to explore how best to treat green water use in LCA.

For the sake of comparison with the approach suggested in this study, Figure 4 shows water use in broccoli supply and consumption assessed using the conventional life cycle approach, which focuses on quantifying total blue water abstracted, whether evaporated or not, and excludes green water and effects from land use. The cropping stage for irrigated cultivation dominates the results. However, contributions from the background system are significant, arising mainly in the 'Home' stage from electricity consumption and in 'Excretion' from toilet use (Muñoz et al. 2008; Milà i Canals et al. 2008). Including green water (as in Fig 1) reduces the overall differences between British and Spanish crops.

\section{Fig. 4}

At least for this case study, the conventional approach to water use in the LCI (Figure 4) gives results similar to those from the method developed in Part I (compare Figures 2 and 4). However, where irrigated cultivation is to be compared in waterabundant and water-scarce countries, the comparison would change dramatically. For instance, Hospido et al. (2009) report similar (blue) water uses for UK and Spanish grown lettuce. Applying the LCIA approach suggested here would show that in terms of potential impact on freshwater ecosystems, water use in Spain is much more significant. 
In the case study presented here, considering the Freshwater Ecosystem Impact (FEI) reveals distinctions between systems that have similar total water usage and smaller differences in other impact categories. In particular, it highlights the differences between the two alternative sourcing countries in terms of water availability. So far, indicator values at a country level have been provided, which allow for inter-national comparisons but would not allow within-country distinctions to be made. However, such regional variations may be captured when relevant; e.g. Chapagain and Orr (2009, Table 4) investigated numerous growing locations within Spain and identified large variation not only in total water volumes used but also in the contribution of blue/green water to the total water volume. Indeed, a river basin or even a watershed level analysis may be much more significant for a spatially dependent resource such as water. Increasing data availability through Geographic Information Systems should facilitate the implementation of such an approach.

In the case of FD, data availability on abstraction and replenishment rates of aquifers will prove critical for the applicability of this impact category.

The Swiss EcoScarcity method 2006 (Frischknecht et al. 2006) also uses the WUPR indicator as a basis to calculate characterisation factors for water scarcity. This method gives more weight to the higher WUPR values (particularly above $10 \%$, which is considered the critical use). Applying the EcoScarcity method (2006) characterisation factors to this case study (results not shown) places even more emphasis on the differences between Spanish and UK-based supply chains. The Swiss EcoScarcity method is attractive as it groups the water use contexts in six criticality classes. This simplifies LCI data collection considerably. Rather than specifying water volumes per country or region (which would require distinction of hundreds of water flows in the LCI), it allows water flows to be simply divided into six water scarcity classes. It can therefore be regarded as a simpler embodiment of the WUPR indicator applied here.

In addition to the scarcity of the water used, the LCA model needs to recognise different modes of dissipation, As discussed in Part I, a more precautionary approach might include total abstraction; i.e. evaporative + non-evaporative use. However, using the total volume of abstracted water would penalise water intensive processes that abstract but immediately return water to the same water body, e.g. cooling water returned with a small change in temperature). When only evaporative use is included in the impact assessment, as in the approach from part I applied here, farms abstracting more water but using it less efficiently (such as ES1 compared to ES2) ${ }^{4}$ apparently cause a smaller impact on freshwater ecosystems (Fig. 3) because the water abstracted but not evaporated is assumed to become available. This conclusion is counterintuitive and its validity may at best not be general. Furthermore, particularly for simple systems involving little food processing as illustrated in this study, the value of distinguishing between evaporative and non-evaporative water use may not justify the additional LCI modelling requirements (see e.g. Table 3). As an alternative solution, other measures of dissipation could be recorded in the LCI. For example, a distinction could be made between 'immediately returned water' (including any volumes of water returned to the abstracted body without significant changes in quality) and 'dissipated water' (including all water not falling in the previous category, e.g. evaporated water, water transferred to another water body etc.). The results should be more informative than the conventional LCA approach, although the LCI modelling complexity would be as challenging as distinguishing evaporative use. In any case, clear guidance needs to be developed on classifying water as 'immediately returned' or 'dissipated' (e.g. when is a change in quality significant).

Recent moves towards a taxation system for groundwater use in Southern Spain might radically change the usage patterns of overexploited aquifers, which would in turn change the calculated ADP and potentially affect the results for FD discussed here. Even without such taxation, the result presented here shows the need for water-saving strategies to be implemented in appropriate areas, such as Murcia, where the greatest improvements would be seen from measures such as more targeted drip irrigation; water re-use; leak and evaporation protection in irrigation reservoirs and canals; better groundwater monitoring, and in some instances, a cap on abstraction to within water recharge rates.

\section{Conclusions, recommendations and perspectives}

The methodological framework proposed by Milà i Canals et al. (2009) and illustrated by the case studies in this paper improves the representation of freshwater use in LCA, enabling local water scarcity to be incorporated in the overall environmental impact assessment. This helps in identifying the "hotspots" of potential impacts to freshwater ecosystems in a production system, as well as guiding investments for water-saving to the activities where they will have greatest benefit. Trade-offs are likely between impacts related to freshwater use and other impacts, which will have to be dealt with case by case.

The methodology proposes evaporation as the indicator of water dissipation, and the case study shows that this metric can be informative. However, other dissipation measures such as 'transfer into other catchments' or 'release further downstream of the hydrological cycle' or 'water returned at a temperature $\mathrm{Z}^{\circ} \mathrm{C}$ above the abstraction" might also provide meaningful results. The feasibility and value of different possible approaches, particularly for processes in the background

\footnotetext{
${ }^{4}$ Table 2 shows how ES1-1 abstracts a total of $(124+53=) 177 \mathrm{~m}^{3}$ tonne ${ }^{-1}$, whereas ES2-1 abstracts $(151+17=) 168 \mathrm{~m}^{3}$ tonne ${ }^{-1}$.
} 
system, should be explored in further case studies. Focussing on the evaporative use of water makes a farm evaporating more water per $\mathrm{kg}$ crop look worse than a farm which abstracts more water but loses it, for example by leakage, before it is evaporated in crop growth.

The case study set out here compares an irrigated crop in a water scarce region with a rain-fed crop in a water abundant region. It quantifies and clarifies the differences between the two but the differences are intuitively obvious: broccoli produced in the UK during the warm months and frozen for consumption in winter has smaller water-related impacts than broccoli imported from Spain. The methodology should be tested with other, less obvious case studies in order to clarify the suitability and necessity of the LCIA characterisation factors and LCI modelling requirements. This study has identified other major sources of water use, besides agriculture, in the life-cycle of vegetables, namely, direct use of water for cooking and sanitation, land use effects on the water cycle, and electricity production. Use of tap water at home (cooking and sanitation) is associated with some evaporative loss, and estimates for this loss should be obtained; however, this use could in any case be treated as dissipative because the water is removed from one catchment and returned to another, usually with lower quality. Further case studies including more intensive uses of land (e.g. systems with greater reliance on mineral resources) or energy (e.g. processed food) may show higher contributions from such interventions.

The Water Footprint (WF) concept and methodology are still being developed, and may benefit from approaches familiar to the LCA community (e.g. allocation; definition of system boundaries; definition of impact pathways). Similarly, the LCA community may benefit from the detailed water accounting framework used in the WF approach in incorporating water use impacts in LCA, as illustrated in this paper. Although there is potential synergy in using these tools together, both carry their own particular strengths that serve differing purposes. For example, an important use of the WF approach is to present impact assessment results on maps of water scarcity where the volumes of water used from each region are highlighted, rather than combining water volumes along a supply chain weighted by characterisation factors depending on water scarcity. Maps are useful for organisations to visualise where their impacts occur and guide strategic decisions, whereas a single score for water impacts as used in LCA is helpful in identifying the environmental hotspots of a product and selecting between different sources and supply chains. The two approaches will therefore continue to develop separately but the challenge is to develop the WF approach ensuring that it is consistent with improvements in the treatment of water use in LCA, and to continue developing LCIA methods for water use consistent with the impact assessment phase of WF.

Acknowledgements The RELU project RES-224-25-0044 (http://www.bangor.ac.uk/relu) funded the data collection for the case study on broccoli LCA. Meteorological data for Lincolnshire were provided by Climate Enquiry Officer UK Met Office, and data for Murcia were provided by Sección de Climatología y Relaciones con los Usuarios Centro Meteorológico Territorial en Murcia. Since the first draft in January 2008, this work has been presented in the $35^{\text {th }}$ LCA Discussion Forum (Zurich, CH, 5 June 2008); the $6^{\text {th }}$ International Conference on LCA in the Agri-Food Sector (Zurich, CH, 12-14 November 2008); and in the Water Footprint Working Group Meeting in Woking (UK), 18 December 2008; comments from and discussions with the participants in these events are kindly appreciated. The thorough comments of two reviewers have improved the clarity and transparency of this paper and are kindly appreciated.

\section{References}

Alcamo J, Henrich T, Rösch T (2000) World Water in 2025-global modeling and scenario analysis for the World Commission on Water for the 21st Century. Centre for Environmental System Research, University of Kassel, Kassel. Available at http://www.usf.unikassel.de/usf/archiv/dokumente/kwws/kwws.2.pdf

Allen RG, Pereira LS, Raes D, Smith M (1998): Crop evapotranspiration - Guidelines for computing crop water requirements. FAO, Rome, Italy. Althaus H-J, Chudacoff M, Hellweg S, Hischier R, Jungbluth N, Osses M, Primas A (2004): Life cycle inventories of chemicals. ecoinvent report No 8. Swiss Centre for Life Cycle Inventories, Dübendorf, Switzerland

Chapagain AK, Hoekstra AY (2004): Water footprints of nations. UNESCO-IHE, Delft, the Netherlands

Chapagain AK, Orr S (2008): UK Water Footprint Report: the impact of the UK's food and fibre consumption on global water resources In: Godalming, UK: WWF-UK.

Chapagain AK, Orr S (2009): An improved water footprint methodology to link global consumption to local water resources: A case study of Spanish tomato consumption. J Environ Manage 90(2):1219-1228

Chapagain AK, Hoekstra AY, Savenije HHG, Gautam R (2006): The water footprint of cotton consumption: An assessment of the impact of worldwide consumption of cotton products on the water resources in the cotton producing countries. Ecol Econ 60(1): 186

Custodio E (2002): Aquifer overexploitation: what does it mean? Hydrogeology Journal 10, 254-277

FAO (1993): CLIMWAT for CROPWAT: A climatic database for irrigation planning and management. Page Developed by: Martin Smith Irrigation and Drainage Paper No. 49. Food and Agriculture Organization of the United Nations, Rome, Italy

FAO (2003): AQUASTAT 2003. Food and Agriculture Organization of the United Nations, Rome, Italy

Frischknecht R, Steiner R, Braunschweig A, Egli N, Hildesheimer G (2006): Swiss ecological scarcity Method: The new version 2006. In The Seventh International Conference on EcoBalance, Nov 14-16, 2006, Tsukuba, Japan, available from www.esu-services.ch/ubp06

Edwards-Jones G, Milà i Canals L, Hounsome N, Truninger M, Koerber G, Hounsome B, Cross P, York EH, Hospido A, Plassmann K, Harris IM, Edwards RT, Day GAS, Tomos AD, Cowell SJ, Jones DL (2008): Testing the assertion that 'local food is best': the challenges of an evidence based approach. Trends Food Sci Tech. 19 (2008) 265-274

Hospido A, Milà i Canals L, McLaren SJ, Clift R, Truninger M, Edwards-Jones G (2009): The role of seasonality in lettuce consumption: a case study of environmental and social aspects. Int J Life Cycle Ass 14(5) 381-391

IWMI (2007): IWMI online climate summary service portal. International Water Management Institute, Sri Lanka

Milà i Canals L, Cowell SJ, Sim S, Basson L (2007a): Comparing Domestic versus Imported Apples: A Focus on Energy Use. Environ Sci Pollut R 14(5) 338-344 
Milà i Canals L, Romanyà J, Cowell SJ (2007b): Method for assessing impacts on life support functions (LSF) related to the use of 'fertile land' in Life Cycle Assessment (LCA). J Clean Prod 15 1426-1440

Milà i Canals L, Muñoz I, Hospido A, Plassmann K, McLaren SJ, Edwards-Jones G, Hounsome B (2008): Life Cycle Assessment (LCA) of Domestic vs. Imported Vegetables. Case studies on broccoli, salad crops and green beans. CES Working Papers 01/08 Available from www.surrey.ac.uk/CES

Milà i Canals L, Chenoweth J, Chapagain AK, Orr S, Antón A, Clift R (2009): Assessing Freshwater Use Impacts in LCA Part I: Inventory Modelling and Characterisation Factors for the Main Impact Pathways. Int J Life Cycle Ass 14(1) 28-42

Muñoz I, Milà i Canals L, Clift R (2008): Consider a spherical man - A simple model to include human excretion in Life Cycle Assessment of food products. J Ind Ecol 12(4) 521-538

Muñoz I, Milà i Canals L, Fernández-Alba A. Life Cycle Assessment of water supply in the Spanish Mediterranean basin: the Ebro river water transfer versus the AGUA Program. Submitted

Smakhtin V, Revenga C, Döll P (2004): Taking into Account Environmental Water Requirements in Global-scale Water Resources Assessments. Comprehensive Assessment Report 2. http://www.iwmi.cgiar.org/assessment/FILES/pdf/publications/ResearchReports/CARR2.pdf

Van der Walt IJ, Struwig A, van Rensburg JRJ (2004): Forestry as a streamflow reduction activity in South Africa: Discussion and evaluation of the proposed procedure for the assessment of afforestation permit applications in terms of water sustainability. GeoJournal 61 173-181

Table 1 Parameters used to calculate direct water use in the cropping stage in the systems studied

Table 2 Direct water used in the cropping stage in the studied systems, per hectare and per tonne of product

Table 3 Estimation of evaporative water use in relevant processes of the background system

Table 4 Results for Depletion of Abiotic Resources, including Freshwater Depletion, in kg Sb-eq/kg broccoli on plate

Fig. 1 'Qualified LCI' results for water use in the life cycle of broccoli assessed using the water footprint approach

Fig. 2 Characterised results of Freshwater Ecosystem impact (FEI), in litres of "ecosystem equivalent water" per kg broccoli on plate

Fig. 3 Relative contribution of each supply chain to different impact categories relative to the highest contribution. LU: Land Use [m²year];

PEU: Primary Energy Use [MJ]; SQ: Soil Quality [measured as soil organic carbon deficit, Milà i Canals et al. 2007b)]; AP: Acidification

Potential; EP: Eutrophication Potential; GWP: Global Warming Potential; POCP: Photochemical Ozone Creation Potential; FEI: Freshwater Ecosystem Impact; ADP: Abiotic Depletion Potential, including Freshwater Depletion. More details of the impact assessment methods can be found in Milà i Canals et al. (2008). Only four supply chains are shown for clarity

Fig. 4 Conventional assessment of (blue) water use in the life-cycle of broccoli (Milà i Canals et al. 2008) 
Table 1 Parameters used to calculate direct water use in the cropping stage in the systems studied

\begin{tabular}{|c|c|c|c|c|c|c|c|c|}
\hline & UK5-1 & UK5-2 & UK6-1 & UK6-2 & ES1-1 & ES1-2 & ES2-1 & ES2-2 \\
\hline Location & Lincolnshire & Lincolnshire & Lincolnshire & Lincolnshire & Murcia & Murcia & Murcia & Murcia \\
\hline - latitude & 52.8 & 52.8 & 53.0 & 53.0 & 37.8 & 37.8 & 37.7 & 37.7 \\
\hline - longitude & -0.1 & -0.1 & -0.1 & -0.1 & -1.5 & -1.5 & -1.2 & -1.2 \\
\hline Planting date & mid-March & $\begin{array}{l}\text { 3rd week of } \\
\text { July }\end{array}$ & April & July & end August & end Feb. & August & Feb. \\
\hline Harvest date & June & October & June & October & late Nov. & May & Nov. & May \\
\hline $\begin{array}{l}\text { Production } \\
\text { system }\end{array}$ & $\begin{array}{l}\text { cover for the } \\
1 \text { st } 1.5 \\
\text { months }\end{array}$ & Open & Open & Open & Open & $\begin{array}{l}\text { Plastic mulch } \\
\text { on soil }\end{array}$ & Open & Open \\
\hline Yield (kg/ha) & 15600 & 15600 & 9600 & 9600 & 17000 & 17000 & 14900 & 14900 \\
\hline $\begin{array}{l}\text { Irrigation water } \\
\text { supplied }\left(\mathrm{m}^{3} / \mathrm{ha}\right)\end{array}$ & & & & & 3000 & 2400 & 2500 & 1100 \\
\hline Type of irrigation & & & & & flood & flood & drip & drip \\
\hline $\begin{array}{l}\text { Irrigation } \\
\text { efficiency }\end{array}$ & & & & & $70 \%$ & $70 \%$ & $90 \%$ & $90 \%$ \\
\hline
\end{tabular}

Table 2 Direct water used in the cropping stage in the studied systems, per hectare and per tonne of product

\begin{tabular}{|c|c|c|c|c|c|c|c|c|c|}
\hline & & UK5-1 & UK5-2 & UK6-1 & UK6-2 & ES1-1 & ES1-2 & ES2-1 & ES2-2 \\
\hline \multicolumn{10}{|l|}{$\begin{array}{l}\text { Water evaporated in } \\
\text { crop production }\end{array}$} \\
\hline Green $\left(\mathrm{m}^{3} / \mathrm{ha}\right)$ & A & 1441 & 1660 & 1580 & 1716 & 884 & 737 & 884 & 774 \\
\hline Blue $\left(\mathrm{m}^{3} / \mathrm{ha}\right)$ & B & & & & & 2100 & 1680 & 2250 & 990 \\
\hline Total $\left(\mathrm{m}^{3} / \mathrm{ha}\right)$ & $\mathrm{C}=\mathrm{A}+\mathrm{B}$ & 1441 & 1660 & 1580 & 1716 & 2984 & 2417 & 3134 & 1764 \\
\hline $\begin{array}{l}\text { Return flows from } \\
\text { irrigation }\left(\mathrm{m}^{3} / \mathrm{ha}\right)\end{array}$ & $\mathrm{D}$ & & & & & 900 & 720 & 250 & 110 \\
\hline Green $\left(\mathrm{m}^{3} /\right.$ tonne $)$ & A/yield & 92 & 106 & 165 & 179 & 52 & 43 & 59 & 52 \\
\hline Blue ( $\mathrm{m}^{3} /$ tonne $)$ & B/yield & & & & & 124 & 99 & 151 & 66 \\
\hline $\begin{array}{l}\text { Total evaporative } \\
\left(\mathrm{m}^{3} / \text { tonne }\right)\end{array}$ & C/yield & 92 & 106 & 165 & 179 & 176 & 142 & 210 & 118 \\
\hline $\begin{array}{l}\text { Non evaporative } \\
\left(\mathrm{m}^{3} / \text { tonne }\right)\end{array}$ & D/yield & & & & & 53 & 42 & 17 & 7 \\
\hline
\end{tabular}

Table 3 Estimation of evaporative water use in relevant processes of the background system

\begin{tabular}{|c|c|c|c|}
\hline Background system process & Related to... & $\%$ of total water use in studied systems & $\begin{array}{l}\text { \% water evap. } \\
\text { (see text) }\end{array}$ \\
\hline GB: electricity medium voltage, at grid & $\begin{array}{l}\text { Cooling, freezing, } \\
\text { packing... }\end{array}$ & $3-4 \%$ (UK systems); $<1 \%$ (ES systems) & $14.5 \%$ \\
\hline GB: electricity low voltage, at grid & $\begin{array}{l}\text { Home cooking and } \\
\text { storage }\end{array}$ & $44-48 \%$ (UK systems); $11-12 \%$ (ES systems) & $13.2 \%$ \\
\hline ES: electricity medium voltage, at grid & $\begin{array}{l}\text { Cooling, packing, } \\
\text { irrigating }\end{array}$ & $<1 \%$ & $7.8 \%$ \\
\hline GB: tap water, at user ${ }^{a}$ & Cooking, toilet use & $43-44 \%$ (UK systems); 11-13\% (ES systems) & $12.5 \%$ \\
\hline ES: tap water, at user ${ }^{a}$ & Plant propagation & $<1 \%$ & $12.5 \%$ \\
\hline RER: corrugated board, recycling fibre, double wall & Packaging & $1 \%$ (ES systems) & $5 \%$ \\
\hline
\end{tabular}

'a this process has been copied from the ecoinvent process 'RER: tap water, at user', with no further changes than the specification of evaporative and nonevaporative water use.

Table 4 Results for Depletion of Abiotic Resources, including Freshwater Depletion, in kg Sb-eq/kg broccoli on plate.

\begin{tabular}{|c|c|c|c|c|c|c|c|c|c|c|}
\hline & ES1-1 & ES1-2 & ES2-1 & ES2-2 & UK5-1 & UK5-2 & UK5-2-Fr & UK6-1 & UK6-2 & UK6-2-Fr \\
\hline $\begin{array}{l}\text { Energy resources } \\
\text { Groundwater. }\end{array}$ & $1.6 \mathrm{E}-02$ & $1.6 \mathrm{E}-02$ & $1.7 \mathrm{E}-02$ & $1.7 \mathrm{E}-02$ & $1.3 \mathrm{E}-02$ & $1.3 \mathrm{E}-02$ & $1.8 \mathrm{E}-02$ & $1.3 \mathrm{E}-02$ & $1.3 \mathrm{E}-02$ & $1.8 \mathrm{E}-02$ \\
\hline $\begin{array}{l}\text { Murcia } \\
\text { Other material }\end{array}$ & $2.4 \mathrm{E}+10$ & $1.9 \mathrm{E}+10$ & $3.9 \mathrm{E}+10$ & $1.7 \mathrm{E}+10$ & $0.0 \mathrm{E}+00$ & $0.0 \mathrm{E}+00$ & $0.0 \mathrm{E}+00$ & $0.0 \mathrm{E}+00$ & $0.0 \mathrm{E}+00$ & $0.0 \mathrm{E}+00$ \\
\hline resources & 4.3E-06 & 4.2E-06 & 8.4E-06 & $8.3-06$ & $4.1-06$ & $4.1-06$ & $4.8-06$ & $4.7-06$ & 4.6E-06 & 5.3-06 \\
\hline TOTAL & $2.4 \mathrm{E}+10$ & $1.9 \mathrm{E}+10$ & $3.9 \mathrm{E}+10$ & $1.7 \mathrm{E}+10$ & 1.3E-02 & 1.3E-02 & $1.8 \mathrm{E}-02$ & $1.3 \mathrm{E}-02$ & 1.3E-02 & $1.8 \mathrm{E}-02$ \\
\hline
\end{tabular}

Fig. 1 Results for water use in the life cycle of broccoli complemented with the water footprint approach. Numerical results provided in the Supportive Information (Table SI.1) 




Fig. 2 Characterised results of Freshwater Ecosystem Impact (FEI), in litres of "ecosystem equivalent water" per kg broccoli on plate. Numerical results provided in the Supportive Information (Table SI.2)

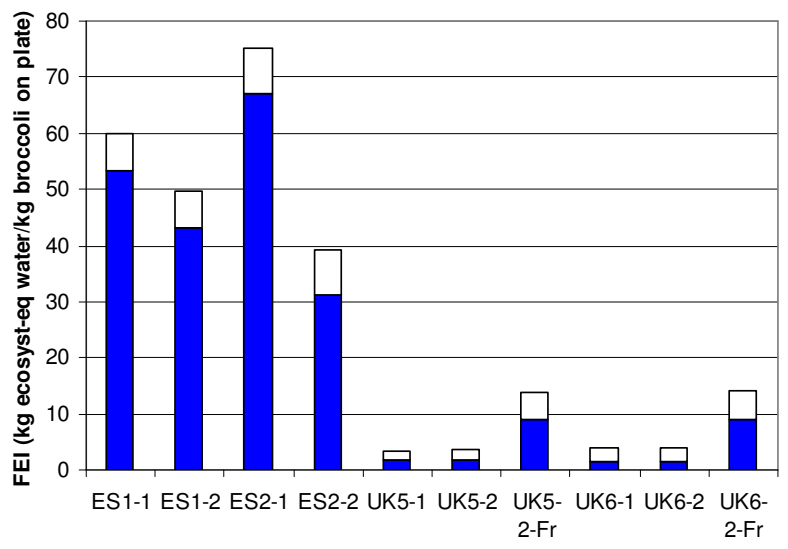

- FEl, from Evaporative Use, Blue $\square \mathrm{FEI}$, from Land Use effects

Fig. 3 Relative contribution of each supply chain to different impact categories relative to the highest contribution. LU: Land Use [m²year]; PEU: Primary Energy Use [MJ]; SQ: Soil Quality [measured as soil organic carbon deficit, Milà i Canals et al. 2007b)]; AP: Acidification Potential; EP: Eutrophication Potential; GWP: Global Warming Potential; POCP: Photochemical Ozone Creation Potential; FEI: Freshwater Ecosystem Impact; ADP: Abiotic Depletion Potential, including Freshwater Depletion. More details of the impact assessment methods can be found in Milà i Canals et al. (2008). Only four supply chains are shown for clarity. Numerical results provided in the Supportive Information (Table SI.3)

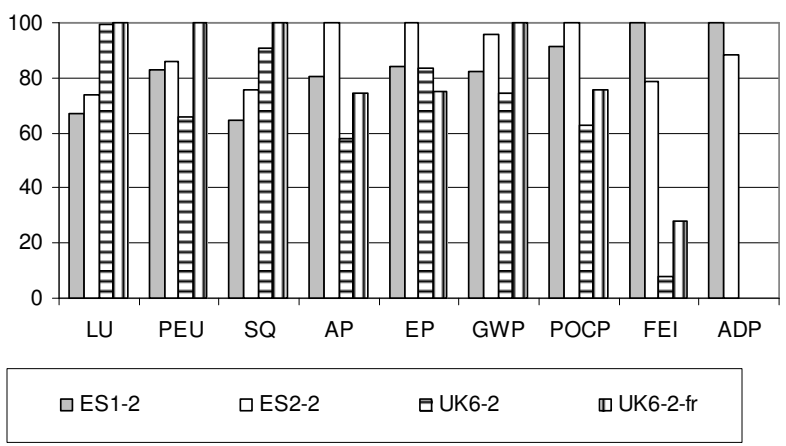


Fig. 4 Total Abstracted (evaporative and non-evaporative) water use in the life-cycle of broccoli (Milà i Canals et al. 2008). Numerical results provided in the Supportive Information (Table SI.4)

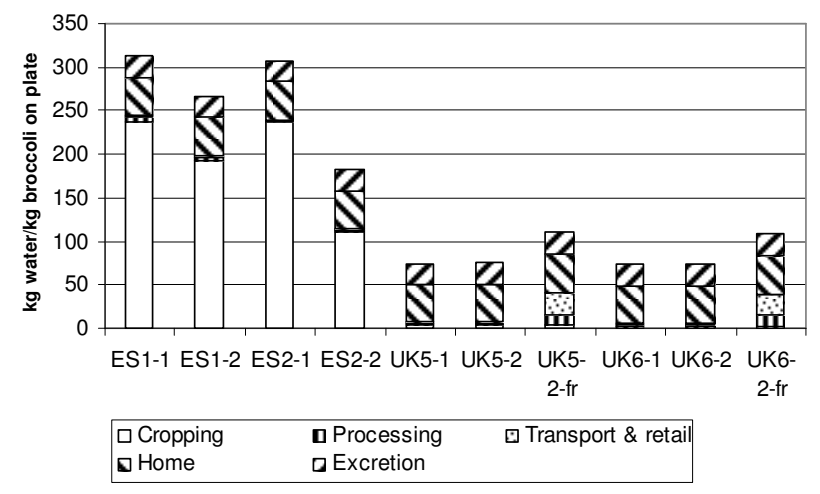

